\title{
Genetic structure from the oldest Jatropha germplasm bank of Brazil and contribution for the genetic improvement
}

\author{
DALILHIA N. DOS SANTOS ${ }^{1}$, JULIANO L. FERREIRA ${ }^{2}$, TESFAHUN A. \\ SETOTAW ${ }^{1}$, GERALDO M.A. CANÇADO ${ }^{3}$, MOACIR PASQUAL ${ }^{1}$, LUCIANA C.N. \\ LONDE ${ }^{4}$, HELOISA M. SATURNINO ${ }^{4}$ and WAGNER A. VENDRAME ${ }^{5}$ \\ ${ }^{1}$ Departamento de Agricultura, Universidade Federal de Lavras, Campus Universitário, 37200-000 Lavras, MG, Brazil \\ ${ }^{2}$ Unidade Pecuária Sul, Empresa Brasileira de Pesquisa Agropecuária, Rodovia \\ BR152, Km 603, Vila Industrial, 96401-970 Bagé, RS, Brazil \\ ${ }^{3}$ Unidade Mista de Pesquisa em Genômica Aplicada a Mudanças Climáticas, Empresa Brasileira de Pesquisa \\ Agropecuária, Av. André Tosello, 209, Campus da Unicamp, 13083-970 Campinas, SP, Brazil \\ ${ }^{4}$ Empresa de Pesquisa Agropecuária de Minas Gerais, Rodovia MG 122, Km \\ 155, Zona Rural, 39525-000 Nova Porteirinha, MG, Brazil \\ ${ }^{5}$ Tropical Research and Education Center, University of Florida, 18905 SW, 280th Street, 33031-3314 Homestead, Florida, USA
}

Manuscript received on April 5, 2016; accepted for publication on May 26, 2016

\begin{abstract}
Jatropha is a potential oilseed crop, which requires mitigating factors such as the low genetic variability of the species. The solution runs through the research of Brazilian germplasm. Attention should be given to the germplasm of jatropha the north of Minas Gerais, because this is the oldest national collection and because this region may be a regions of jatropha diversity due to selection pressure arising from environmental adversities. Therefore, the objective of this study was to investigate the genetic diversity of 48 accessions of collection from Empresa de Pesquisa Agropecuária de Minas Gerais (EPAMIG), using SSR and ISSR markers. The results showed low genetic diversity, but some individuals stood out as $J$. mollissima (48), J. podagrica (47), Mexican accessions (42, 43, 44 and 45) and some national accessions $(28,29,41$ and 46). Therefore, aiming to increase the genetic variability and improve the effectiveness of jatropha breeding programs, it is suggested to explore such as parental accessions to generate commercial hybrids. This fact implies the possibility to support future production of jatropha, since this culture may be an important source of income, especially for small farmers living in semiarid regions of Brazil.
\end{abstract}

Key words: genetic diversity, Jatropha curcas, molecular markers, oilseed crop.

\section{INTRODUCTION}

Modern civilization has provided us with a comfortable life, achieved through economic growth and industrialization, but at the cost of climate change. Therefore, it is important to secure

Correspondence to: Dalilhia Nazaré dos Santos

E-mail: dalilhians@gmail.com an energy source with sustainable environmental development in order to maintain such comfortable life without further environmental disruption (Moniruzzaman et al. 2016). There is great demand for renewable energy sources and jatropha (Jatropha curcas L.) is one of the potential candidate crops to be exploited as a source of biofuel. Jatropha is a small perennial tree with 
desirable characteristics as a biofuel crop, such as rapid growth, easy propagation, drought tolerance, insect and pest resistance, and particularly seeds with high oil content and quality for biodiesel and bio jet fuel production (Pandey et al. 2012, Dias et al. 2012, Edrisi et al. 2015).

However, jatropha is still considered undomesticated and in the past, commercial plantations were established with no attention to vegetative and reproductive characteristics, as well as cultivation practices. Jatropha plantations did not meet commercial expectations due to the absence of a good commercial variety, lack of systematic breeding programs, and the absence of desired genetic variability within the species (Moniruzzaman et al. 2016).

Therefore, in order to expand the commercial plantation of jatropha in Brazil, it is necessary to investigate the genetic diversity of jatropha collections available in the country and to provide scientific knowledge that support the future breeding activities. In Brazil, a jatropha collection located in a semiarid region of the northern part of the state of Minas Gerais is of great interest because this is the oldest collection in the country and should show sufficient genetic variability that can be exploited in breeding programs aiming at high yielding commercial cultivars. This is supported by Dias et al. (2012) who suggested this collection could represent an important center of diversity of jatropha, while Freitas et al. (2011) indicated this collection showed high level of phenotypic variability among the accessions.

Furthermore, because this jatropha germplasm collection is located in a semiarid region of Brazil, this is relevant for plant breeding programs as many of the desirable characteristics may have been selected and fixed through the process of adaptation to adversity inherent from semiarid regions, such as deciduousness (Dias et al. 2012). Deciduousness of jatropha is an adaptive characteristic of the species to resist drought and guarantee survival in harsh conditions, such as those in the semiarid region of North Minas Gerais state.

Dehgan and Schutzman (1994) observed that jatropha's adaptive responses to cold and/or dry conditions are observed in association with its geographical distribution. The speciation of jatropha in the neotropics has been faster in seasonally dry regions such as scrublands (savanna grasslands) and caatinga. Therefore, it is possible the selection of jatropha accessions for genetic improvement programs with great chances of success (Dias et al. 2012).

Currently, one of the most efficient techniques for the genetic characterization of germplasm collections is the use of molecular markers. Molecular markers can detect genetic differences at the DNA level and in contrast to phenotypic evaluations, they are not affected by environmental factors. Among the molecular markers available, microsatellites or SSRs (simple sequence repeats) and ISSRs (inter simple sequence repeats) are widely used to study the genetic diversity and population structure of many plant species. SSR markers are codominant and multiallelic, whereas ISSR markers are dominant and multilocus (Borém and Caixeta 2009, Faleiro 2007). The combination of two molecular markers can provide a more accurate inference regarding the genetic and genomic composition of a germplasm collection.

Therefore, the objective of this study was to investigate the genetic diversity and the population structure of jatropha accessions found in the oldest germplasm collection in Brazil using molecular markers. A combination of SSRs and ISSRs will be used in this study. The genetic information obtained is of great importance to support future genetic improvement programs of jatropha in Brazil.

\section{MATERIALS AND METHODS}

\section{PLANT MATERIAL AND DNA EXTRACTION}

All activities in this study were performed at Universidade Federal de Lavras (UFLA), in the city 
of Lavras, Minas Gerais state, Brazil. All accessions of jatropha (Jatropha curcas L.) used in the study are shown in Table I and were obtained from the germplasm collection of EPAMIG, located in the city of Nova Porteirinha, in the northern region of Minas Gerais state, Brazil.

For DNA extraction, young healthy leaves were collected from each accession and placed in a paper bag with proper accession identification. The samples were transported to the molecular biology laboratory at UFLA and stored at $-80{ }^{\circ} \mathrm{C}$ in ultra-low freezer. Leaf samples were lyophilized until complete dryness and subsequently grinded, followed by genomic DNA extraction using the method described by Nunes et al. (2011).

\section{SSR MARKER ANALYSIS}

Eleven primers previously described to be polymorphic for the jatropha genus were selected for this study. A detailed description of primers with their motif and sequence is shown in Table II.

For primer amplifications, the reaction was performed with the final volume of $25 \mu \mathrm{L}$ containing
$50 \eta \mathrm{g}$ of DNA, $6 \mu \mathrm{L}$ of $5 \mathrm{X}$ reaction buffer, $1.5 \mathrm{mM}$ $\mathrm{MgCl}_{2}, 200 \mu \mathrm{M}$ of each dNTP, $0.2 \mu \mathrm{M}$ of each primer (Sigma, USA) and 2U of Taq DNA polymerase (Go Taq Flexi, Promega, USA). Samples were amplified in a gradient thermal cycler (Gradient Multigene, Labnet International, USA) using a touchdown program, with initial denaturation at $94^{\circ} \mathrm{C}$ for $5 \mathrm{~min}$, followed by 8 denaturation cycles at $94^{\circ} \mathrm{C}$ for $50 \mathrm{~s}$, with the annealing temperature decreased $1^{\circ} \mathrm{C}$ in each cycle from 62 to $55^{\circ} \mathrm{C}$ for $45 \mathrm{~s}$ and $72^{\circ} \mathrm{C}$ for $1 \mathrm{~min}$. This step was followed by 33 amplification cycles with denaturation at $94^{\circ} \mathrm{C}$ for $50 \mathrm{~s}$, annealing at $54^{\circ} \mathrm{C}$ for $45 \mathrm{~s}$ and extension at $72^{\circ} \mathrm{C}$ for $1 \mathrm{~min}$. Finally an amplification was concluded with final extension at $72^{\circ} \mathrm{C}$ for $10 \mathrm{~min}$.

The amplified PCR product was run on a $6 \%$ denaturing polyacrylamide gel using $60 \mathrm{~W}$ power for variable duration according to the expected size of the alleles. Then the resulting gels were stained with silver nitrate according to the method described by Creste et al. (2001). After drying overnight at room temperature, the gels were photographed on a UV light box.

TABLE I

Jatropha accessions with their laboratory and field identification numbers (IDs).

\begin{tabular}{cccccc}
\hline ID & Genotype & ID & Genotype & ID & Genotype \\
\hline $\mathbf{1}$ & BAG-JC-36 & $\mathbf{1 7}$ & BAG-JC-19 & $\mathbf{3 3}$ & BAG-JC-06 \\
$\mathbf{2}$ & BAG-JC-37 & $\mathbf{1 8}$ & BAG-JC-21 & $\mathbf{3 4}$ & BAG-JC-07 \\
$\mathbf{3}$ & BAG-JC-38 & $\mathbf{1 9}$ & BAG-JC-22 & $\mathbf{3 5}$ & BAG-JC-08 \\
$\mathbf{4}$ & BAG-JC-41 & $\mathbf{2 0}$ & BAG-JC-23 & $\mathbf{3 6}$ & BAG-JC-09 \\
$\mathbf{5}$ & BAG-JC-42 & $\mathbf{2 1}$ & BAG-JC-24 & $\mathbf{3 7}$ & BAG-JC-12 \\
$\mathbf{6}$ & BAG-JC-43 & $\mathbf{2 2}$ & BAG-JC-25 & $\mathbf{3 8}$ & BAG-JC-13 \\
$\mathbf{7}$ & BAG-JC-44 & $\mathbf{2 3}$ & BAG-JC-26 & $\mathbf{3 9}$ & BAG-JC-15 \\
$\mathbf{8}$ & BAG-JC-45 & $\mathbf{2 4}$ & BAG-JC-27 & $\mathbf{4 0}$ & BAG-JC-48 \\
$\mathbf{9}$ & BAG-JC-46 & $\mathbf{2 5}$ & BAG-JC-28 & $\mathbf{4 1}$ & BAG-JC-71 \\
$\mathbf{1 0}$ & BAG-JC-47 & $\mathbf{2 6}$ & BAG-JC-29 & $\mathbf{4 2}$ & BAG-JC-72 \\
$\mathbf{1 1}$ & BAG-JC-31 & $\mathbf{2 7}$ & BAG-JC-30 & $\mathbf{4 3}$ & BAG-JC-72 \\
$\mathbf{1 2}$ & BAG-JC-32 & $\mathbf{2 8}$ & BAG-JC-01 & $\mathbf{4 4}$ & BAG-JC-71 \\
$\mathbf{1 3}$ & BAG-JC-33 & $\mathbf{2 9}$ & BAG-JC-02 & $\mathbf{4 5}$ & BAG-JC-84 \\
$\mathbf{1 4}$ & BAG-JC-16 & $\mathbf{3 0}$ & BAG-JC-03 & $\mathbf{4 6}$ & J. curcas (dwarf) \\
$\mathbf{1 5}$ & BAG-JC-17 & $\mathbf{3 1}$ & BAG-JC-04 & $\mathbf{4 7}$ & J. podagrica \\
$\mathbf{1 6}$ & BAG-JC-18 & $\mathbf{3 2}$ & BAG-JC-05 & $\mathbf{4 8}$ & J. mollissima \\
\hline
\end{tabular}


TABLE II

SSR jatropha primers used to evaluate 48 jatropha accessions, with respectively sequences, annealing temperatures (Ta) and allele sizes (bp).

\begin{tabular}{|c|c|c|c|}
\hline Primer & Sequence & Ta $\left({ }^{\circ} \mathrm{C}\right)$ & bp \\
\hline \multirow[t]{2}{*}{ Jcps9 } & D:GTACTTAGATCTCTTGTAACTAACAG & 48.0 & 147 \\
\hline & R:TATCTCTTGTTCAGAAATGGAT & & \\
\hline \multirow[t]{2}{*}{ Jcps 21} & D:CCTGCTGACAGGCCATGATT & 54.8 & 190 \\
\hline & R:TTTCACTGCAGAGGTAGCTTGTATA & & \\
\hline \multirow[t]{2}{*}{ Jcds 58} & D:TCCATGAAGTTTGCTGGCAAT & 54.0 & 109 \\
\hline & R:AGGTCATCTGGTAAAGCCATACC & & \\
\hline \multirow[t]{2}{*}{ Jcds66 } & D:CCTACGAGTGATTGGATAGTTTCTCA & 54.0 & 218 \\
\hline & R:TCTTCCATCAAGAGTCGTTGGGCA & & \\
\hline \multirow[t]{2}{*}{ Jcps 10} & D:CATCAAATGCTAATGAAAGTACA & 46.5 & 112 \\
\hline & R:CACACCTAGCAAACTACTTGCA & & \\
\hline \multirow[t]{2}{*}{ Jcps24 } & D:GGATATGAAGTTTCATGGGACAAG & 51.0 & 204 \\
\hline & R:TTCATTGAATGGATGGTTGTAAGG & & \\
\hline \multirow[t]{2}{*}{ Jcps41 } & D: AACACACCATGGGCCACAGGT & 56.6 & 114 \\
\hline & R:TGCATGTGTGCGGGTTTGATTAC & & \\
\hline \multirow[t]{2}{*}{ Jct 27} & D: GCCATTAGAATGGACGGCTA & 60.0 & 235 \\
\hline & R: TGCGTGAAGCTTTGATTTGA & & \\
\hline \multirow[t]{2}{*}{ Jcps20 } & F: ACAGCAAGTGCACAACAATCTCA & 55.0 & 224 \\
\hline & R:TACTGCAGATGGATGGCATGA & & \\
\hline \multirow[t]{2}{*}{ Jct16 } & F: GCCTCCAGCATCTTTCAATC & 60.0 & 103 \\
\hline & R: AАCAАТССССАТТССТССТC & & \\
\hline \multirow[t]{2}{*}{ Jct59 } & F: GGTGACTCCTGAATGCTTGG & 60.0 & 187 \\
\hline & R: TACCCTGAAACTCCCAGGAA & & \\
\hline
\end{tabular}

\section{ISSR MARKER ANALYSIS}

In this study we used five ISSR primers previously indicated to be polymorphic in different crops, such as strawberries (Arnau et al. 2002). The detailed description of primers is shown in Table III.

The amplification reactions for the ISSR analysis were performed in a final volume of 25 $\mu \mathrm{L}$ containing $50 \eta \mathrm{g}$ of DNA, $7.5 \mu \mathrm{L}$ of $5 \mathrm{x}$ reaction buffer, $1.5 \mathrm{mM}$ of $\mathrm{MgCl}_{2}, 200 \mu \mathrm{M}$ of each dNTP, $0.8 \mu \mathrm{M}$ primers (Sigma, USA) and $2.4 \mathrm{U}$ of Taq DNA polymerase (Go Taq Flexi, Promega, USA). The reactions were conducted in a gradient thermal cycler (Gradient Multigene, Labnet International, USA). Samples were amplified with initial denaturation at $95^{\circ} \mathrm{C}$ for $2 \mathrm{~min}$ and then subjected to 40 cycles of amplification. Each cycle involved the following steps: $95^{\circ} \mathrm{C}$ for $45 \mathrm{~s}$, annealing at 47 $51^{\circ} \mathrm{C}$ (depending on the initiator used) during 1 min, and primer extension at $72^{\circ} \mathrm{C}$ for $2 \mathrm{~min}$. After 40 cycles, the samples were maintained at $72^{\circ} \mathrm{C}$ for $5 \mathrm{~min}$ for final extension. Two independent amplifications were performed for each primer to certify the reliability and reproducibility of the data bands produced by each primer (Arnau et al. 2002).

The amplified products ( $5 \mu \mathrm{L}$ of samples) were subjected to gel electrophoresis in the presence of ethidium bromide $(0.3 \mathrm{mg} / \mathrm{mL})$ in $1.5 \%$ agarose immersed in TBE buffer [ $90 \mathrm{mM}$ Tris-borate $(\mathrm{pH}$ 8.0 ) and $10 \mathrm{mM}$ EDTA] for 4 hours under $110 \mathrm{~V}$. The gels were subsequently photographed under UV light.

\section{DATA ANALYSIS}

Before the molecular marker data were subjected to statistical analysis, the amplified products were codified according to the type of molecular markers. 
TABLE III

ISSR primers used to evaluate the 48 jatropha accessions, with their respective sequences and annealing temperatures (Ta).

\begin{tabular}{|c|c|c|}
\hline Primer & Sequence & Ta \\
\hline *VBV $(\mathrm{AC}) 7$ & 5'VBVACACACACACACAC3` & $51^{\circ} \mathrm{C}$ \\
\hline *BDB $(\mathrm{CA}) 7$ & 5'BDBCACACACACACACA3' & $51^{\circ} \mathrm{C}$ \\
\hline *HBH $(\mathrm{CT}) 7$ & 5'НВНСТСТСТСТСТСТСТ3` & $47^{\circ} \mathrm{C}$ \\
\hline *GCV (TC)7 & 5'GCVTCTCTCTCTCTCTC3’ & $49^{\circ} \mathrm{C}$ \\
\hline *BDV (AG)7 & 5`BDVAGAGAGAGAGAGAG3` & $47^{\circ} \mathrm{C}$ \\
\hline
\end{tabular}

${ }^{*} \mathrm{~V}, \mathrm{~B}, \mathrm{H}$ and $\mathrm{D}$, respectively, indicate that all nitrogenous bases are in equimolar concentration, except for T; all bases are in equimolar concentration, except for A; all bases are in equimolar concentration, except for $\mathrm{G}$; and all bases are in equimolar concentration, except for $\mathrm{C}$.

For the SSR markers, the allelic profile was codified according to the number of polymorphic alleles produced in jatropha accessions from each SSR primers. The number of allele per locus was designated numerically from 1 to the maximum number produced from each primer. The allelic profiles generated by the ISSR primers were codified as 1 for the presence of the specified band, and 0 for the absence of the band. Finally the codified data obtained from each molecular marker were analyzed statistically.

Phenetic trees were produced using the UPGMA clustering method based on "CS Chord" distance (Cavalli-Sforza and Edward 1967) estimated from the allelic profile of the SSR marker. This statistical analysis was performed using "Powermarker version 3.25" (Liu and Muse 2005). The data obtained from the ISSR marker analysis were used to produce the allele sharing distance (ASD), and employed to produce a dendrogram based on the UPGMA clustering method. To understand the population structure of jatropha accessions, data from SSR and ISSR markers were subjected to the Bayesian model-based clustering analysis using the "Structure 2.3.3" software (Pritchard et al. 2000). In this analysis 10000 burn-in, $100000 \mathrm{MCMC}$, with correlated allele model was employed. To determine the appropriate number of clusters $(\mathrm{K})$, the analysis was performed from $\mathrm{k}=1$ to $\mathrm{k}=12$ with 21 iterations for each K. Finally, the appropriate number of clusters was determined using Structure Harvester (Earl and vonHoldt 2012), the online software program according to Evanno et al. (2005). The PCoA based on the SSR and ISSR markers was produced using the GenAlex version 6.41 software (Peakall and Smouse 2006). Finally the same software was used to estimate the correlations between the distance produced by ISSR and SSR markers using Mantel's test.

\section{RESULTS}

GENETIC DIVERSITY OF JATROPHA GERMPLASM BY SSRS

For all 11 SSR markers, the genetic parameters such as number of alleles, expected heterozygosity ( $\mathrm{He})$, observed heterozygosity (Ho) and polymorphic information content (PIC) (data not shown) were produced to test the efficiency of each primer used to study the genetic diversity of the jatropha accessions. The number of alleles observed varied from 2 to 5. The expected (He) and observed (Ho) heterozygosity ranged from 0.0428 to 0.6155 $($ mean $=0.4014)$ and 0.0000 to $1.0000($ mean $=$ $0.6470)$, respectively. Primers Jcps 24 presented the lowest PIC value $(0.0423)$ while Jct 27 showed the highest (0.5392).

The phenetic tree produced between individuals based on SSR markers is shown in Figure 1. Based on the dendrogram produced, it is possible to observe four cluster groups, where accessions 
47 and 48 are isolated from the remaining of the accessions. This was expected, since these two accessions are separate species, J. podagrica (accession 47) and J. mollissima (accession 48), respectively. The third group includes one accession of Brazilian origin (acession41), and accessions of Mexican origin (accessions 42, 43, 44, and 45). Moreover, the branching pattern in the dendrogram among these five individuals indicated that these accessions have discrete genetic variability among them, which demonstrates their potential for use in genetic improvement programs of the species. The fourth and largest group is comprised of accessions of Brazilian origin, and showed distinction from the remaining of the individuals. Within the Brazilian collection, accessions 41 and 46 are more divergent and can be selected for breeding programs aiming at the development of highly productive cultivars.

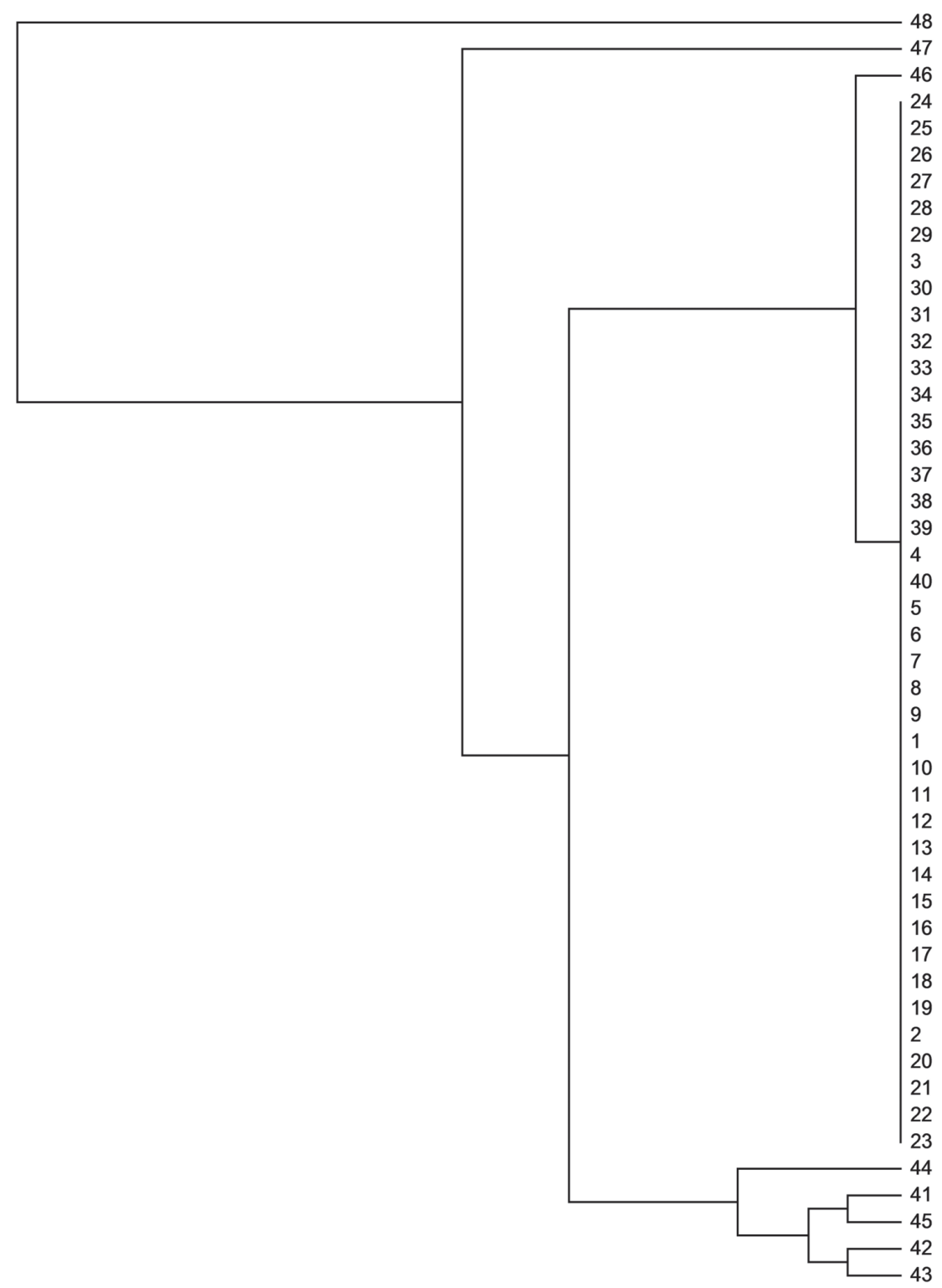

0.1

Figure 1 - UPGMA phenetic tree obtained using data from the SSR markers, showing the genetic relationships among the 48 of jatropha accessions, identified according to Table I. 
The Bayesian model-based clustering analysis using the SSR data clustered the 48 accessions into 2 or 3 cluster groups with delta $\mathrm{k}=2$ and delta $\mathrm{k}=3$ (Figure $2 \mathrm{a}-\mathrm{b}$ ). Similarly, the Mexican accessions (42 to 45) and accession 41 (the Brazilian collection) grouped together in the UPGMA. Accession 46 (the dwarf jatropha) was clustered with other jatropha accessions.

\section{GENETIC DIVERSITY OF JATROPHA GERMPLASM BY ISSRs}

The five selected ISSR markers were able to detect 23 loci. The numbers of loci amplified by these primers were 5 for the primer $\mathrm{VBV}, 3$ for $\mathrm{BDB}$, 4 for BDB, 7 for GCV and 4 for HBH. Due to the smaller size of the jatropha genome compared with that of other species, ISSR markers amplified fewer loci. To better understand the genetic structure of the accessions in this study, a phenetic tree was produced. Although the dendrogram produced 5 distinct groups (Figure 3), results demonstrated low polymorphism among the jatropha accessions selected in this study.
The first two groups include $J$. mollissima and $J$. podagrica, which are more distant from other jatropha accessions. Most of the Mexican accessions (42, 44, and 45) were grouped in the same cluster with the Brazilian jatropha collection, except for accession 43. The fourth cluster group was formed by accessions 28 and 29 of the Brazilian jatropha collection.

The structure clustering analysis clustered the jatropha accessions into two cluster groups (Figure 2c). The largest group contains the 46 accessions that include all Brazilian and Mexican collections. The second group includes two accessions from different species, accessions 47 (J. mollissima) and 48 (J. podagrica).

Similarly, the ISSR markers detected low genetic variability among the Brazilian jatropha collections. Furthermore, there was a clear genetic distinction between the Brazilian jatropha collection and most of the accessions from Mexico, J. mollissima and $J$. podagrica. The mantel test between the genetic distance produced by the SSR and ISSR markers showed significant correlation $(r=0.699, p<$
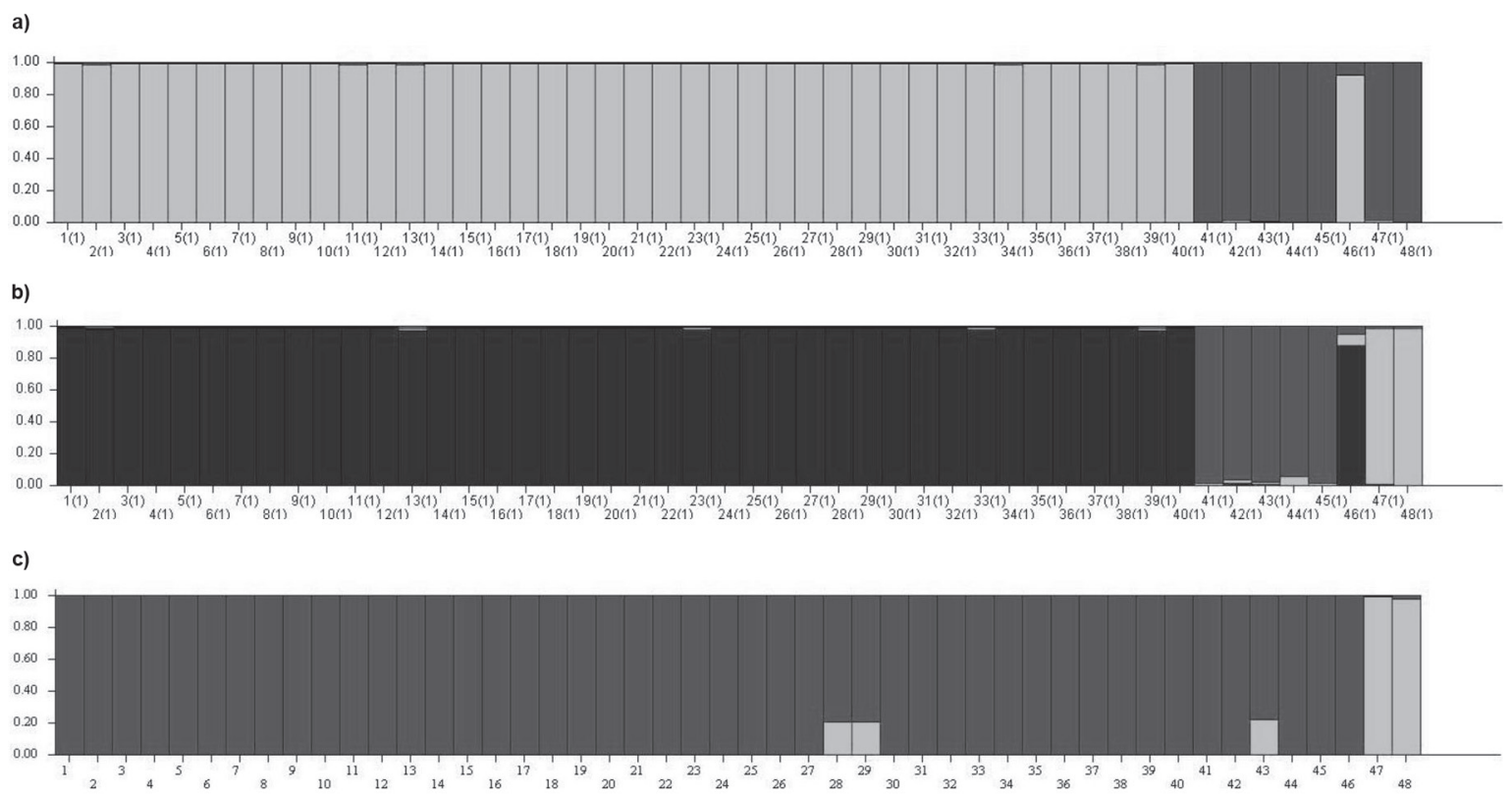

Figure 2 - Structure grouping of 48 jatropha accessions. (a) based on 11 SSR profiles and delta k = 2; (b) based on 11 SSR profiles and delta $\mathrm{k}=3$; (c) based on 5 ISSR profiles and delta $\mathrm{k}=2$; The vertical axis comprehend the relative membership coefficient and the horizontal axis the individual identification according to Table I. 
0.01), which indicates the existence of congruence between the distances produced by these markers.

\section{DISCUSSION}

\section{GENETIC DIVERSITY EVALUATION BY}

MOLECULAR MARKERS

In this study, the estimated number of alleles per primer was similar to that reported in the literature.
Na-ek et al. (2011) observed 2-4 alleles per locus, whereas Bressan et al. (2012) found 2-8 alleles per locus when they developed new SSR markers for jatropha. In addition, the mean $\mathrm{He}(0.4478)$ and Ho (0.2656) reported by Na-ek et al. (2011) were approximately the same as those reported in our study. Bressan et al. (2012) also reported the He $(0.25$ to 0.77 , mean $=0.66)$ and $\mathrm{Ho}(0.24$ to 0.90 ,

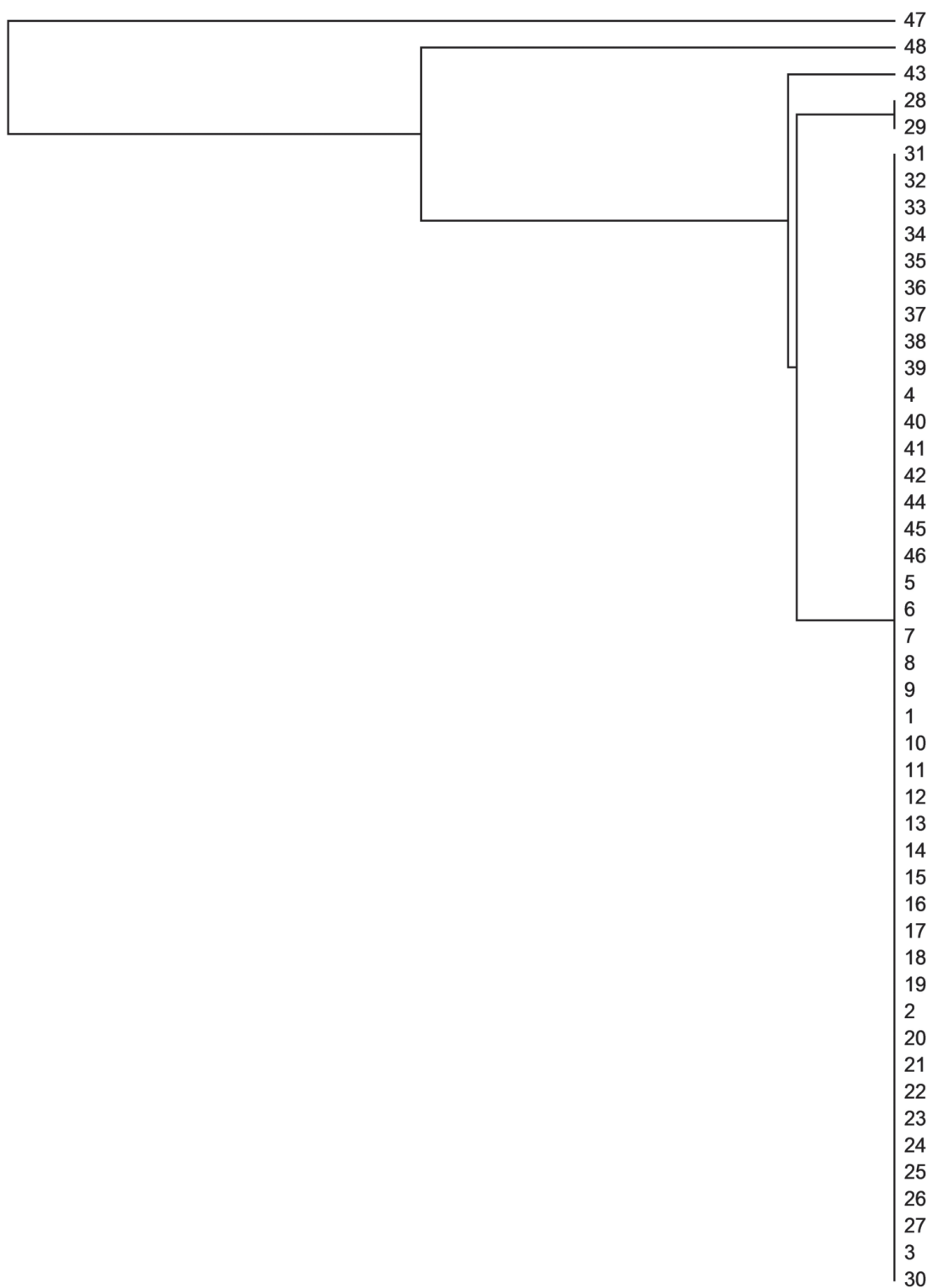

Figure 3 - UPGMA phenetic tree obtained using data from the ISSR markers, showing the genetic relationships among the 48 of jatropha accessions, identified according to Table I. 
mean $=0.53)$ for the same species. The maximum PIC value estimated in this study was for Jct 27 (0.5392) and the lowest for Jcps24 (0.0423). This indicates that primer Jct 27 is more informative than other primers and can be explored in future genetic characterization studies of the species.

The use of SSR markers can generate robust results to study the genetic variability of plants because the markers amplify the SSR regions of the plant genome that are highly interchangeable and consequently keep most of the polymorphism found in a particular species. However, the genetic variability obtained by SSR markers in this study was low. One reason for this can be an inherent feature of the microsatellite regions in the genome of jatropha. Wang et al. (2011) observed low genetic variation in SSR regions of the jatropha genome among different genotypes. Similar to our study, Mukherjee et al. (2011) reported a monomorphic amplification pattern for most of the SSR markers used to study the genome of jatropha genotypes. The results reported here using SSR markers also confirm the low genetic variability within the jatropha accessions evaluated. Similar results have been reported by other studies using different jatropha populations (Na-ek et al. 2011, Phumichai et al. 2011).

Similarly, the ISSR markers also detected narrow genetic variability among the jatropha accessions evaluated. Alkimim et al. (2013) evaluated jatropha accessions from Minas Gerais using ISSR and RAPD markers and reported low genetic diversity. These results are also similar to those obtained in studies using ISSR markers in Brazil (Grativol et al. 2011) and in different countries, such as China (Chen et al. 2011) and India (Kumar et al. 2011).

In this study, genetic distinction was observed for Mexican jatropha accessions. This is confirmed by Pecina-Quintero et al. (2011), who evaluated Mexican jatropha collections using AFLP and found diversity indices of $60 \%$. The genetic diversity between the Mexican germplasm and other jatropha populations is not fully understood, although it brings great opportunities for local breeding programs by providing new sources of genetic variation.

In addition to the advantage of the diversity observed in Mexican accessions, accessions 28, 29, 41 and 46 can be exploited for future breeding programs because they showed high level of genetic diversity using both SSR and ISSR markers. All of these accessions can be selected as a parent to produce commercial hybrid cultivars. An individual of particular interest is accession 46, which has short size (dwarf) and can be exploited in breeding programs to improve plant architecture and facilitate the harvesting process.

Interspecific variability was observed among $J$. mollissima, J. podagrica and J. curcas, as these are different species within the same genus. Therefore, interspecific crosses can be performed, as a strategy to introduce new traits into the population of $J$. curcas, provided there is no reproductive incompatibility among species. It has been reported that $J$. podagrica is compatible with both $J$. curcas and J. podagrica (Sujatha 2006).

GENETIC DIVERSITY OF JATROPHA ACESSIONS IN NORTHERN MINAS GERAIS

In this study, the evaluation of genetic diversity by SSR and ISSR molecular markers returned similar results. Both markers revealed low genetic variability in the jatropha germplasm collection located in the north region of Minas Gerais.

Low genetic variability within domestic jatropha germplasm collections was also reported worldwide in studies using SSRs (Pamidimarri et al. 2009, Kumar et al. 2010, Phumichai et al. 2011) and ISSRs (Achten et al. 2010). Mukherjee et al. (2011) observed approximately $75 \%$ of genetic similarity among jatropha germplasm collections from all over the world.

The low genetic variability in jatropha may be the result of its evolution process, as this species 
may have undergone a process of genetic drift over time, due to the founder effect (Heller 1996) and bottleneck effect (Veasey et al. 2011). Another possible reason for the low genetic variability in jatropha might be related to the vegetative propagation method used by the commercial farmers worldwide, which tends to maintain the genetic fidelity of individuals (Ovando-Medina et al. 2011).

The information obtained in this study supports the assumption made by Dias et al. (2012), which indicates that the north region of Minas Gerais can be an important center of diversity, based on the high variability observed in the agronomic traits of jatropha in this region. Because the jatropha germplasm collection in northern Minas Gerais is the oldest in Brazil, it may have produced adaptive genetic variability through time.

The phenotypic variations observed can be a result of environmental effect, such as the constant water deficits and high temperatures that have an effect over the development and reproduction of jatropha (Laviola et al. 2010. Shabanimofrad et al. 2013), as well as epigenetic effects which may play a crucial role in the adaptive evolution to changing environment (Sahu et al. 2013). This is very important since jatropha accessions with high phenotypic variability showed low level of genetic diversity, supporting that the species has high phenotypic plasticity. Therefore, most of the morphological variability might be inheritable from one generation to another and care must be exercised for use of this information in genetic improvement programs of the species. If genotypes are selected based only on morphological traits that are highly influenced by environment, such improved traits might not remain stable future generations.

Based on the results observed in this study, we suggest that selection should be performed under various environmental conditions and with large number of repetitions to reduce the effect of the environment and improve the selection efficiency. We also suggest the use of highly polymorphic markers, such as SNPs to be used in molecular assisted selection programs for jatropha.

We reinforce the importance and value of selecting the Mexican accessions, the Brazilian accessions (28, 29, 41 and 46), and $J$. podagrica for breeding programs of jatropha to increase the genetic base and produce hybrids cultivars, since these accessions have cross compatibility with $J$. curcas.

In conclusion, the results of this study and consequently the suggestions presented can contribute to the effectiveness of jatropha breeding programs. The practical implication of improving the future breeding program of jatropha is granting the sustainability of jatropha production in the future. As a source of biofuel, this crop can serve as an important source of income, especially for small-scale farmers that live in the semiarid regions of Brazil.

\section{ACKNOWLEDGMENTS}

The authors would like to thank Coordenação de Aperfeiçoamento de Pessoal de Nível Superior (CAPES), Conselho Nacional de Desenvolvimento Científico e Tecnológico (CNPq) and Fundação de Amparo à Pesquisa do Estado de Minas Gerais (FAPEMIG) for providing funding to this project.

\section{REFERENCES}

ACHTEN WMJ ET AL. 2010. Towards domestication of Jatropha curcas. Biofuels 1: 91-107.

ALKIMIM ER, SOUSA TV, SOARES BO, SOUZA DA, JUHÁSZ ACP, NIETSCHE S AND COSTA MR. 2013. Genetic diversity and molecular characterization of physic nut genotypes from the active germplasm bank of the Agricultural Research Company of Minas Gerais, Brazil. Afr J Biotechnol 12: 907-913.

ARNAU G, LALLEMAND J AND BOURGOIN M. 2002. Fast and reliable strawberry cultivar identification using inter simple sequence repeat (ISSR) amplification. Euphytica 129: 69-79.

BORÉM A AND CAIXETA ET. 2009. Marcadores Moleculares. $2^{\mathrm{a}}$ ed. Viçosa, Viçosa, $532 \mathrm{p}$. 
BRESSAN EA, SCOTTON DC, FERREIRA RR, JORGE EC, SEBBENN AM, GERALD LTS AND FIGUEIRA A. 2012. Development of microsatellite primers for Jatropha curcas (Euphorbiaceae) and transferability to congeners, Am J Bot 99: 237-239.

CAVALLI-SFORZA LL AND EDWARD AWF. 1967. Phylogenetic analyses: models and estimations procedures. Evolutions 21: 550-570.

CHEN K, REN P, YING C, JIANG Q AND JIA X. 2011. Genetic relationships among Jatropha curcas L. clones from Panzhihua, China as revealed by RAPD and ISSR. Afr J Agric Res 6: 2582-2585.

CRESTE S, TULMANN-NETO A AND FIGUEIRA A. 2001. Detection of simple sequence repeat polymorphisms in denaturing polyacrilamide sequencing gels by silver staining. Plant Mol Biol Rep 19: 299-306.

DEHGAN B AND SCHUTZMAN B. 1994. Contributions toward a monograph of neotropical jatropha: phenetic and phylogenetic analyses. Ann Missouri Bot Garden 81: 349367.

DIAS LAS, MISSIO RF AND DIAS DCSF. 2012. Antiquity, botany, origin and domestication of Jatropha curcas (Euphorbiaceae), a plant species with potential for biodiesel production. Genet Mol Res 11: 2719-2728.

EARL DA AND VONHOLDT BM. 2012. STRUCTURE HARVESTER: a website and program for visualizing STRUCTURE output and implementing the Evanno method. Conserv Genet Res 4: 359-361.

EDRISI SA, DUBEY RK, TRIPATHI V AND BAKSHIA M. 2015. Jatropha curcas L.: A crucified plant waiting for resurgence. Renew Sust Ener Rev 41: 855-862.

EVANNO G, REGNAUT S AND GOUDET J. 2005. Detecting the number of clusters of individuals using the software STRUCTURE: a simulation study. Mol Ecol 14: 26112620.

FALEIRO FG. 2007. Marcadores Genético-Moleculares aplicados a programas de conservação e uso de recursos genéticos. Embrapa, Brasília, 102 p.

FREITAS RG, MISSIO RF, MATOS FS, RESENDE MD AND DIAS LAS. 2011. Genetic evaluation of Jatropha curcas: an important oilseed for biodiesel production. Genet Mol Res 10: 1490-1498.

GRATIVOL C, LIRA-MEDEIROS CF, HEMERLY AS AND FERREIRA PC. 2011. High efficiency and reliability of inter-simple sequence repeats (ISSR) markers for evaluation of genetic diversity in Brazilian cultivated Jatropha curcas L. accessions. Mol Biol Rep 38: 42454256.

HELLER J. 1996. Physic nut Jatropha curcas L. promoting the conservation and use of underutilized and neglected crops. Institute of Plant Genetics and Crop Plant Research, Gatersleben/ International Plant Genetic Resources Institute, Rome, 66 p.
KUMAR S, ANAND KGV, PAMIDIMARRI DVNS, SARKAR T, REDDY MP, RADHAKRISHNAN T, KAUL T, REDDY MK AND SOPORI SK. 2010. Stable genetic transformation of Jatropha curcas via Agrobacterium tumefaciens-mediated gene transfer using leaf explants. Ind Crop Prod 32: 41-47.

KUMAR S, KUMARIA S, SHARMA SK, RAO SR AND TANDON P. 2011. Genetic diversity assessment of Jatropha curcas L. germplasm from Northeast India. Biomass Bioenergy 35: 3063-3070.

LAVIOLA BG, ROSADO TB, BHERING LL, KOBAYASHI AK AND RESENDE MDV. 2010. Genetic parameters and variability in physic nut accessions during early developmental stages. Pesq Agropec Bras 45: 1117-1123.

LIU K AND MUSE SV. 2005. Power marker: Integrated analysis environment for genetic marker data. Bioinformatics 21: 2128-2129.

MONIRUZZAMAN M, YAAKOB Z AND KHATUN R. 2016. Biotechnology for jatropha improvement: A worthy exploration. Renew. Sust Energ Rev 54: 1262-1277.

MUKHERJEE P, VARSHNEY A, JOHNSON TS AND JHA TB. 2011. Jatropha curcas: a review on biotechnological status and challenges. Plant Biotech Rep 5: 197-215.

NA-EK Y, WONGKAEW A, PHUMICHAI T, KONGSIRI N, KAVEETA R, REEWONGCHAI T AND PHUMICHAI C. 2011. Genetic diversity of physic nut (Jatropha curcas L.) revealed by SSR markers. J Crop Sci Biotech 14: 105-110.

NUNES CF, FERREIRA JL, FERNANDES MCN, BREVES SS, GENEROSO AL, SOARES BDF, DIAS MSC, PASQUAL M, BORÉM L AND CANÇADO GMA. 2011. An improved method for genomic DNA extraction from strawberry leaves. Cien Rural 41: 1383-1389.

OVANDO-MEDINA I, ESPINOSA-GARCÍA FJ, NÚÑEZFARFÁN JS AND SALVADOR-FIGUEROA M. 2011. State of the art of genetic diversity research in Jatropha curcas. Sci Res Essays 6: 1709-1719.

PAMIDIMARRI DVNS, SHAIK GM, RAHMAN H, PRAKASH CR, SINGH S AND MUPPALA PR. 2009. Cross species amplification ability of novel microsatellites isolated from Jatropha curcas and genetic relationship with sister taxa cross species amplification and genetic relationship of Jatropha using novel microsatellites. Mol Biol Rep 38: 1383-1388.

PANDEY VC, SINGH K, SINGH JS, KUMAR A, SINGH B AND SINGH RP. 2012. Jatropha curcas: a potential biofuel plant for sustainable environmental development. Renew Sustain Energy Rev 16: 2870-2883.

PEAKALL R AND SMOUSE PE. 2006. GENALEX 6: genetic analysis in excel: population genetic software for teaching and research. Mol Ecol Notes 6: 288-295.

PECINA-QUINTERO V, ANAYA-LOPEZ JL, COLMENERO AZ, GARCIA NM, COLIN CAN, BONILLA JLS, AGUILAR-RANGEL MR, LANGARICA HRG AND 
BUSTAMANTE DJM. 2011. Molecular characterisation of Jatropha curcas L. genetic resources from Chiapas, México through AFLP markers. Biomass Bioenerg 35: 1897-1905.

PHUMICHAI C, PHUMICHAI T, KONGSIRI N, WONGKAEW A, SRIPICHIT P AND KAVEETA R. 2011. Isolation of 55 microsatellite markers for Jatropha curcas and its closely related species. Biol Plantarum 55: 387-390.

PRITCHARD JK, STEPHENS M AND DONNELLY P. 2000. Inference of population structure using multilocus genotype data. Genetics 155: 945-959.

SAHU PP, PANDEY G, SHARMA N, PURANIK S, MUTHAMILARASAN M AND PRASAD M. 2013.
Epigenetic mechanisms of plant stress responses and adaptation. Plant Cell Rep 32: 1151-1159.

SHABANIMOFRAD M, RAFII MY, WAHAB PEM, BIABANI AR AND LATIF MA. 2013. Phenotypic, genotypic and genetic divergence found in 48 newly collected Malaysian accessions of Jatropha curcas L. Ind Crops Prod 42: 543-551.

SUJATHA M. 2006. Genetic improvement of Jatropha curcas L. possibilities and prospects. Indian J For 8: 58-65.

VEASEY EA ET AL. 2011. Processos evolutivos e a origem das plantas cultivadas. Ciênc Rural 41: 1218-1228.

WANG CM ET AL. 2011. A first generation microsatellite and SNP based linkage map of Jatropha. PLoS One 6: e23632. 